(2) Open Access Full Text Article

\title{
A new way to understand chemical carcinogenesis and cancer prevention
}

This article was published in the following Dove Press journal:

Research and Reports in Medicinal Chemistry

17 January 2014

Number of times this article has been viewed

\section{Friedrich H Schmidt \\ Retired, Schramberg, Germany}

Correspondence: Friedrich H Schmidt Langenberg 72, D-78I44 Schramberg,

Germany

Tel +49 77298247

Email fhsdelta@aol.com
Abstract: The $\Delta$ values in this article have been developed by the author to estimate the electrophilic reactivity and carcinogenic potency of molecules. If a certain value of $\Delta$ is regarded as the peak of carcinogenicity, then the substances with $\Delta$ values that fall short of this peak, or that go beyond this peak, have a decrease in carcinogenicity. Keeping this principle in mind should help in avoiding the medicinal use of substances that are suspected to be carcinogenic.

Keywords: carcinogens, structures, chemistry, delta values, carcinogenic strength

\section{Introduction}

Chemical carcinogens are seen as primary reagents in the etiology of cancer. They may bond covalently or noncovalently to DNA, RNA, and proteins. In the initiation of cancer, carcinogens mutate genes and alter the transcription of the genome. They show no common structures, and many of them are activated by metabolic alteration; alkylation, oxidation, or dealkylation.

The $\Delta$ values developed and described by the author are indicators of the electrophilicity of chemicals and carcinogenic strength. Using these values, both a carcinogenic and an anticarcinogenic principle can be worked out.

\section{Structure and chemistry of carcinogens}

Although a great amount of information on the toxic and pharmacologic properties of organic compounds exists, our knowledge of the mechanisms of those agents, which chemically influence the environment and even cause cancer, is relatively limited. ${ }^{1} \mathrm{We}$ are especially concerned with alkylating agents, which have a wide range of effects on living systems. Many alkylating agents are useful drugs, a few are essential nutrients, many are of technical value, and all are toxic in sufficient doses. The toxic and pharmacologic effects of organic compounds appear to result from covalent as well as noncovalent bonds and, thus, from irreversible as well as reversible interactions with cellular molecules. ${ }^{2}$ Today, most oncologists regard chemical carcinogens as primary agents in the etiology of a large fraction of human cancers.

The term "cancer" means a quasipermanent alteration of the cellular phenotype involving the control of mitosis. Conceivably, this tumor phenotype could be produced by heritable changes in the cellular genotype (DNA) or by quasipermanent alterations in the transcription of the genome. Therefore, the carcinogen must interact with one or more macromolecules (DNA, RNA, or proteins) that control cell division. 
Chemical carcinogens show no common structural features. However, if they are not alkylating agents per se, all of them have to be converted metabolically by enzymes to their ultimate carcinogenic form. All ultimate carcinogens are strong electrophilic reactants that interact with nucleophilic sites in biological macromolecules. Figure 1 explains the process of alkylation. An important enzyme system that changes the electrophilic state of a molecule, or breaks it down into metabolites, is $\mathrm{P} 450$ oxidase which is found in the endoplasmic reticulum and in cellular membranes.

One of the objectives in studies of chemical carcinogenesis is the identification of critical macromolecular targets in both the initiation and promotion steps. Rapidity and persistence of initiation are consistent with DNA mutation (which may be prevented by repairing enzymes), but epigenetic mechanisms are also possible in the form of carcinogen binding to RNA or proteins. Covalent bonds are established between the electrophile and the nucleophile, where generally a weak nucleophilic group is lost from the strong electrophilic reagent and a weak electrophile such as $\mathrm{H}+$ is displaced from the strong nucleophile. However, another type of electrophile, the free radical, contains unpaired electrons. These electron-deficient species can move off $\mathrm{H}$ atoms from molecules, and thus generate new free radicals, in hit-and-run attacks. They can also combine covalently with other free radicals.

Guanine is the most nucleophilic base and can be attacked at the N3, N7, N2, O6, and C8 atoms; adenine at N1, N3, and $\mathrm{N} 7$; cytosine at $\mathrm{N} 3$ and $\mathrm{O} 3$; and thymine at $\mathrm{O} 2$ and $\mathrm{O} 4$. Even the backbone phosphate oxygen atoms are getting attacked, which can mean changing the interaction sites of histones.

In particular, the $\mathrm{S}$ atoms of methionine and cysteine in the proteins are getting attacked, in addition to the ring nitrogen of histidine and tyrosine. In carcinogens, the $\mathrm{C}$ atoms are

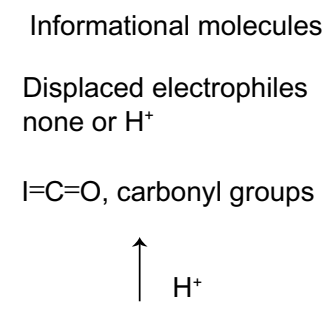

Nucleophilic sites: $-\mathrm{S},-\mathrm{SH}$, $-\mathrm{N},-\mathrm{NH},-\mathrm{CH},-\mathrm{C}-\mathrm{OH}, \mathrm{P}-\mathrm{OH}$ (bases of DNA)

\section{$\longleftarrow$ Interaction $\longrightarrow$}

Figure I The process of alkylation. Abbreviation: DNA, deoxyribonucleic acid. largely electrophilic, but a few contain electrophilic $\mathrm{N}$ atoms and, likely, some $\mathrm{S}$ and $\mathrm{O}$ atoms in an electrophilic state.

Substances such as cytostatics, including N-mustard, diazobutane, diepoxybutane, methanesulfonic acid, cyclophosphamide, busulfan, melphalan, and cisplatin are called direct working alkylating substances because they either get bound themselves in toto at the nucleophilic site or work by transferring alkyl groups on to $\mathrm{SH}^{-}, \mathrm{NH}_{2}^{-}, \mathrm{COOH}^{-}$, and phosphate groups. This results in the deformation of the genetically acting molecules via failures with the transport of genetic information and blocking both the separation of helical strands and mitosis.

For some carcinogens this means dealkylation loss of carcinogenic groups, provided by repair mechanisms, and detoxification. Other carcinogens have to be alkylated to act as ultimate carcinogens. Dialkylnitrosamines, for example, have to be oxidatively dealkylated to be alkylating species and to react with nucleophiles. The carcinogenic efficiency of many reagents is positively correlated to their reactivity with respect to DNA, RNA, and proteins. For most of the aromatic hydrocarbons, such as benz(a)pyrene, benz(a)anthracene, and 3 -methylcholanthrene, the active form as carcinogen is the diol epoxide. After all, we have to conclude that at least one of the diols or epoxides must be, in the process of cancerization, transferred to DNA, RNA, or proteins.

Our knowledge of how the transfer of an alkyl or acyl group affects the genetic code is incomplete. One of the possible results is the total ambiguity in transcription ${ }^{1}$ or replication. It is known that the transfer of genetic information can be profoundly disturbed by this.

According to Szent-Györgyi, ${ }^{3}$ the storage, transfer, and retrieval of genetic information in genes is dependent on the stable and harmonic helical conformation of base pairs. The interruption of base pairing disturbs the transport of genetic information, which results in failures in the production of messenger and transfer RNA, ribosomes, and in the sequential synthesis of amino acids and proteins.

In noncovalent interactions, the functional polar or nonpolar groups of carcinogens bind to receptor sites, in most cases by loose interaction in the van der Waals forces. Promoting agents very often act by this type of interference. Some of the polar groups also serve as hydrogen acceptors ( $-\mathrm{O}-$, ethers, carbonyls, ketones, aldehydes, acids, esters, amides, and amine nitrogens) or as hydrogen donors ( $\mathrm{NH}$, amines, amides, and thiols/SH). Hydrophobic bonding includes the nonpolar hydrocarbon groups of lipids and the lipophilic side chains, especially $\mathrm{CH}_{3}{ }^{-}$of amino acids in polypeptides. 
The binding of functional groups is often loose. Covalent binding results in irreversible interactions that tend to be more toxic and are also more apt to be allergenic. Most molecules can bond to a receptor through more than one binding component (eg, benzanthracene with respect to its epoxides bonds by means of three receptor sites to a protein, or nucleic acids). Therefore, receptor function means interplay of steric and bonding factors (van der Waals forces, electron transfer complexing, and/or hydrophobic bonding).

Because a great majority of protein molecules contain a high amount of amino acids with nonpolar side chains, hydrogen bonds are considered one of the most important factors contributing to the stability of the tertiary structure of many native proteins. Hydrophobic binding between nonpolar substances consists of the approach of two or more nonpolar molecules, surrounded by hydration spheres, until they reach a distance equal to their van der Waals radius. Hydrogen binding contributes to possible configurational changes of the tertiary protein structure that may accompany the binding of a chemical compound. Other stabilizations of protein chains, RNA, and DNA are provided by the pairing of polar groups (S proton acceptors and SH donors, and $\mathrm{S}-\mathrm{S}$ bridges).

Promoters, such as phenobarbital and carbon tetrachloride, and cocarcinogens support the initiation of cancer. Promoters are actually noncarcinogenic by themselves, but cocarcinogens such as hormones are occasionally able to promote cancer. Because hormones enhance the proliferation and growth of cells, they are regarded as potential carcinogens. It is proposed that steroid hormones affect the fate of those somatic cells that are genetically predisposed to become cancer cells. The different behavior of the male and the female sexual hormones is purported to be based on a kind of antagonism in binding to the cell receptors: Estrogens with $\mathrm{C} 17$ keto groups transfer two sulfhydryl groups of a histone molecule to an $\mathrm{S}-\mathrm{S}$ bond, so that RNA polymerase II can be attached to a certain DNA sequence. This procedure allows the formation of RNA and induces protein/enzyme synthesis (eg, DNA polymerase) and, thus, an uncontrolled enzyme-mediated cell proliferation.

In contrast to estrogen, testosterone reactivates the nucleic receptor and stabilizes the histone shield of DNA by the reduction of $\mathrm{S}-\mathrm{S}$ bridges to $\mathrm{S}-\mathrm{H}$ groups by means of its $\mathrm{C} 17 \mathrm{OH}$ group. The specificity of a receptor is not absolute, so it will be occupied by more or less structurally similar molecules or forced to change its conformation by antagonistic hormones, which induce or inhibit the synthesis of enzymes.
Chemical carcinogens often share no common factors. The dissimilarity is easily seen if we compare the molecular weight, chemical structure, and steric configuration of the vast majority of known chemical carcinogens. If we consider the processes of cancer initiation and promotion and the influences of cocarcinogens, as well as the activation of carcinogens by the metabolism and enzymes, hormones, and possibly vitamins, we cannot deny a lack of understanding of the structure and the mechanism of action of carcinogens. To understand the structure-effect relations between carcinogens and genetic substances, a receptor-like interaction must be imagined between the functional groups of genetic molecules and the side groups of effective substances. Covalent bonds can be formed, and active interactions without structural bonds by van der Waals forces are briefly possible. Corresponding physical factors such as interatomic distances, symmetry, polarity and electrophilic or electrophobic intereffects have to be present. Then, an exchange of chemical and genetic information can take place even between molecules with very different configurations.

It should be a scientific goal to reduce the existing physical and chemical complexity in the interplay between reactant and receptor to a more conceivable model.

\section{$\Delta$ values as indicators of carcinogenicity}

The author ${ }^{4-6}$ has suggested a model in which the binary logarithms of atomic weights and fractions of binary number rows are assigned to the spatial position of atoms in the molecule compound and, with this model, determines the amount of influence of all atoms on each other. If the position of an atom is valued as 1 , its neighbor is $-1 / 2$, the next is $+1 / 4$, the following is $-1 / 8$, and so on. Thus, stored chemical information in molecules can be calculated as a binary number. The author developed the so-called $\Delta$ values to get a practical device at hand for being able to judge chemical reactivity of molecules as well as properties like carcinogenicity.

$\Delta$ values are calculated by the following formula:

$$
\mathrm{H}=(-1)^{\mathrm{n}} \sum 2^{-\mathrm{n}} \mathrm{ld} A W^{\mathrm{i}},
$$

where $\mathrm{AW}^{\mathrm{i}}$ is the atomic weights of series.

In Figure 2, the calculation of $\Delta$ values explains the production of $\Delta$ values. Figure 3 reflects the structures of nitrosamines, the $\Delta$ values of their functional groups, and the mortality $\left(\mathrm{LD}_{50} \mathrm{~g} / \mathrm{kg}\right)$ of those carcinogens as far as it is given by Druckrey et $\mathrm{al}^{7}$ and O'Conner. ${ }^{8}$ 
Atom $1=\mathrm{Id}$ AW $1 \mathrm{x}$ fractions of atoms class 1

+ Id AW $2 x$ fractions of atoms class 2

$+\ldots+\ldots$

(calculation algorithm of $\Delta-$ values)

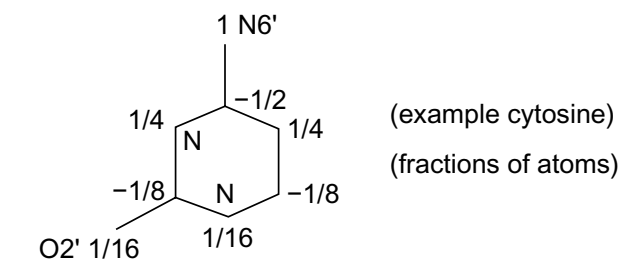

$\Delta \mathrm{N}=1+1 / 4+1 / 16=21 / 16 \mathrm{Id} A W(\mathrm{~N})=5.00$

$\Delta C=-1 / 2+1 / 4-2 / 8=-1 / 2$ Id $A w(C)=-1.79$

$\Delta \mathrm{O}=1 / 16$ Id AW $(\mathrm{O})=0.25$

$\Sigma \Delta \mathrm{N} 6{ }^{\prime}=3.46$

$\Delta$ - values glycine and cytosine
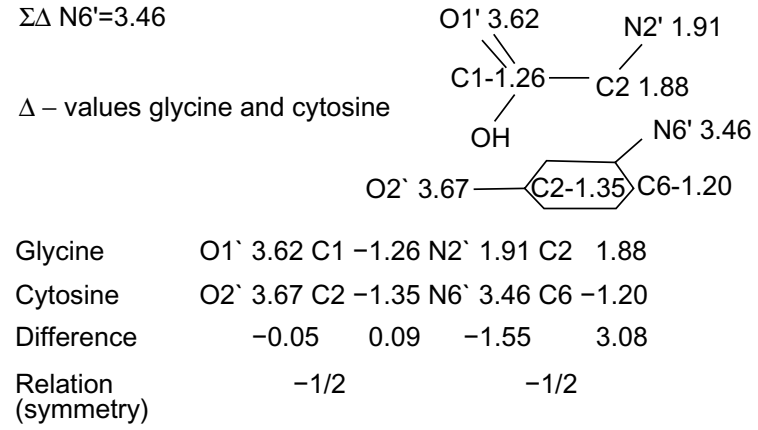

Figure 2 Calculation of $\Delta$ values.

Abbreviation: $\mathrm{AW}$, atomic weight.

\begin{tabular}{|c|c|c|c|}
\hline \multicolumn{2}{|c|}{ Basic structure $0=\mathrm{N}-\mathrm{N}<_{\mathrm{R} 2}^{\mathrm{RT}}$} & $\begin{array}{l}\text { Most } \\
\text { electrophilic } \\
\text { atoms }\end{array}$ & $\begin{array}{l}\text { Mortality } \\
\text { LD }_{50} \mathrm{~g} / \mathrm{kg}\end{array}$ \\
\hline 1. Dimethyln & $\mathrm{R} 1=\mathrm{R} 2=\mathrm{CH}_{3}$ & C3.03 02.16 & 0.4 \\
\hline $\begin{array}{l}\text { 2. M benzyln } \\
\text { 3. M allyln }\end{array}$ & $\begin{array}{l}\mathrm{R} 2= \\
\mathrm{R} 2=\mathrm{Cn} 3\end{array}$ & $\begin{array}{l}\mathrm{C} 2.8502 .24 \\
\mathrm{C} 2.8002 .26\end{array}$ & 0.33 \\
\hline 4. M amyln & $\mathrm{R} 2=\mathrm{Cn} 5$ & $\mathrm{C} 2.7402 .29$ & 0.33 \\
\hline 5. M heptyln & $\mathrm{R} 2=\mathrm{Cn} 7$ & $\mathrm{C} 2.7202 .30$ & 4.6 \\
\hline 6. M nonyln & $\mathrm{R} 2=\mathrm{Cn} 9$ & $\mathrm{C} 2.7202 .30$ & \\
\hline 7. M undecyln & $\mathrm{R} 2=\mathrm{Cn} 11$ & $\mathrm{C} 2.7202 .30$ & \\
\hline 8. M tridecyln & $\mathrm{R} 2=\mathrm{Cn} 13$ & $\mathrm{C} 2.7202 .30$ & \\
\hline 9. M tetradecyln & $\mathrm{R} 2=\mathrm{Cn} 14$ & C2.72 02.30 & \\
\hline 10. $M$ dodecyln & $\mathrm{R} 2=\mathrm{Cn} 12$ & $\mathrm{C} 2.7202 .30$ & \\
\hline 11. M decyln & $\mathrm{R} 2=\mathrm{Cn} 10$ & $\mathrm{C} 2.7202 .30$ & \\
\hline $\begin{array}{l}\text { 12. M octyln } \\
\text { 13. M hexyln } \\
\text { 14. M butyln }\end{array}$ & $\begin{array}{l}\mathrm{R} 2=\mathrm{Cn} 8 \\
\mathrm{R} 2=\mathrm{Cn} 6 \\
\mathrm{R} 2=\mathrm{Cn} 4\end{array}$ & 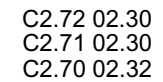 & \\
\hline 15. NNMM-hydoxam & hine $\mathrm{R} 2=\mathrm{O}-\mathrm{C}$ & $\mathrm{C} 2.6802 .33$ & \\
\hline 16. M phenylethyln & $\mathrm{R} 2=\mathrm{C}$ & C2.66 02.34 & 3.4 \\
\hline 17. M ethyln & $\mathrm{R} 2=\mathrm{C}_{2}-\mathrm{H}_{5}$ & $\mathrm{C} 2.5802 .37$ & 0.42 \\
\hline $\begin{array}{l}\text { 18. Dipropyln } \\
\text { 19. Cyclopropyl }\end{array}$ & $\begin{array}{r}\mathrm{R} 1=\mathrm{R} 2=\mathrm{C}_{3} \mathrm{H}_{7} \\
\mathrm{O}=\mathrm{N}\end{array}$ & $\mathrm{C} 2.4802 .38$ & 1.15 \\
\hline 20. M methanoln & $\mathrm{R} 2=\mathrm{CH}_{2}-\mathrm{OH}$ & C2.53 02.40 & \\
\hline 21. M phenyln & $\mathrm{R} 2={ }^{2}$ & $\mathrm{C} 2.4602 .43$ & 3.4 \\
\hline 22. Diamyln & $\mathrm{R} 1=\mathrm{R} 2=\mathrm{Cn} 5$ & $\mathrm{C} 2.4102 .43$ & 48 \\
\hline 23. Butylbutanoln & $\mathrm{R} 1=\mathrm{Cn} 4$ & $\mathrm{C} 2.3502 .46$ & 3.9 \\
\hline 24. Ethylethanoln & $\begin{array}{l}\mathrm{R} 2=\mathrm{C}_{4} \mathrm{H}_{8} \mathrm{OH} \\
\mathrm{R} 1=\mathrm{Cn} 2 \\
\mathrm{R} 2=\mathrm{C}_{2} \mathrm{H}_{4} \mathrm{OH}\end{array}$ & $\mathrm{C} 2.1702 .47$ & 0.6 \\
\hline 25. N-n morpholine & $=\mathrm{N}-\mathrm{N}<$ & 02.48 & 1.3 \\
\hline 26. Ethylpropyln & $\mathrm{R} 1=\mathrm{Cn} 2 \mathrm{R} 2=\mathrm{Cn} 3$ & C2.18 02.49 & 0.23 \\
\hline 27. Dibutyln & $\mathrm{R} 1=\mathrm{R} 2=\mathrm{Cn} 4$ & C2.35 02.49 & 3.9 \\
\hline 28. N-n-piperidine & $\mathrm{O}=\mathrm{N}-\mathrm{N}$ & 02.49 & 1.4 \\
\hline 29. Diethyln & $\mathrm{R} 1=\mathrm{R} 2=\mathrm{Cn} 2$ & $\mathrm{C} 2.3002 .60$ & 0.06 \\
\hline 30. Nn-pyrrolidine & $\mathrm{O}=\mathrm{N}-\mathrm{N}$ & 02.60 & 3.9 \\
\hline
\end{tabular}

Figure 3 Nitrosamines.

Abbreviations: $M$, methyl; $n$, nitroso.
Dialkylnitrosamines have to be oxidatively dealkylated at one of the alkyl chains to become carcinogenic. Only dimethylnitrosamine acts as a molecule in toto. The resulting carcinogenic potency of the dealkylated compound results from the remaining alkyl chain and the number of its remaining atoms.

The carcinogenic potency of a functional group of a nitrosamine gets a numeric value as $\Delta$. The process of the calculation of $\Delta$ values has been described elsewhere. ${ }^{4,5}$ For deciding carcinogenicity, the $\Delta$ value of functional groups in nitrosamines comprises parts of all participating atoms of a molecule. If the mean value of the mortality of nitrosamine molecules destined to be $\mathrm{LD}_{50}$ has been classed with a 1 , then any dealkylated compound possesses a carcinogenicity that is smaller or bigger than 1 , depending on whether the count of the remaining atoms in the remaining alkyl chain of a nitrosamine is an even or odd number. By using this variable, mortality factors can be interpreted.

Figure 4 shows how like regular nitrosamines, 1,2Dimethylhydrazine must be dealkylated with one of the side groups. The resulting $\Delta$ value of the remaining methyl group is 2.63 at the lower end of the carcinogenic spectrum. Accordingly, only weak liver carcinogenicity is seen in rats.

1,1-Dimethylhydrazine possesses a group with $\Delta 3.32$ at the upper border of carcinogenicity. 1-hydroxymethyl-2 methylhydrazine, as an oxidative intermediate of 1,2-DMH (1,2-Dimethylhydrazine), has a $\Delta$ value of 2.90 with $\mathrm{OH}$, dimethylformamide has a value of 3.07 with $\mathrm{CH}_{3}$, and<smiles>CN(C)N</smiles>

1,1-Dimethylhydrazine<smiles>CN(C)[N+](=O)O</smiles>

Dimethylnitramine<smiles>CN(C)C=O</smiles>

Dimethylformamide

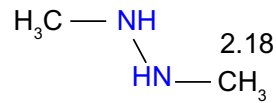

1,2-Dimethylhydrazine

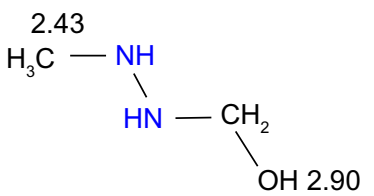

1-hydroxymethyl-2 methylhydrazine

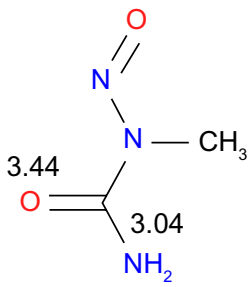

$\mathrm{N}$-methyl-N-nitrosourea
Figure 4 Chemicals similar to nitrosamines. 
dimethylnitramine has a value of 3.15 with $\mathrm{OH}$. Nitromethylurethane also has a distinct carcinogenicity.

$\mathrm{N}$-methyl-N-nitrosourea possesses a high amount of reactivity $(\mathrm{O} \Delta 3.44)$ and is the most potent carcinogen of this type of alkylating agents in the group with $\mathrm{NH}_{2} \Delta 3.04$. The related compound $\mathrm{N}$-ethyl-N-nitrosourea (not depicted here) shows two groups ( $\mathrm{NH} \Delta 3.26$ and $\Delta \mathrm{OH} 3.66$ ) and is very toxic.

All aromatic hydrocarbons presented in Figure 5 have to be converted to their N-hydroxy compounds, which are the ultimate or proximate carcinogenic forms.

Plain DMAB (dimethylaminoazobenzene) is judged controversial by researchers, but the calculated $\Delta$ value supports the presumed carcinogenic strength given in Figure 5.

$\mathrm{N}$-hydroxy-2-acetylaminofluorene (N-OH-2-AAF) works as another proximate or ultimate after getting activated out of 2-AAF and works via alkylation of DNA (C8 of guanine).

The polycyclic hydrocarbons as presented in Figures 6 and 7 have to be metabolically activated to become carcinogenic, via methylation of the plain molecules and additional forming of epoxides and diols by oxidases in liver mitochondria, according to research by Heidelberger and Moldenhauer., ${ }^{910}$ Then the methyl groups of the rings reach their ultimate carcinogenic strength, as reflected in Figure 6.

Historically, plain, unoxidized benz(a)pyrene and benz(a)anthracene have been regarded as the active forms

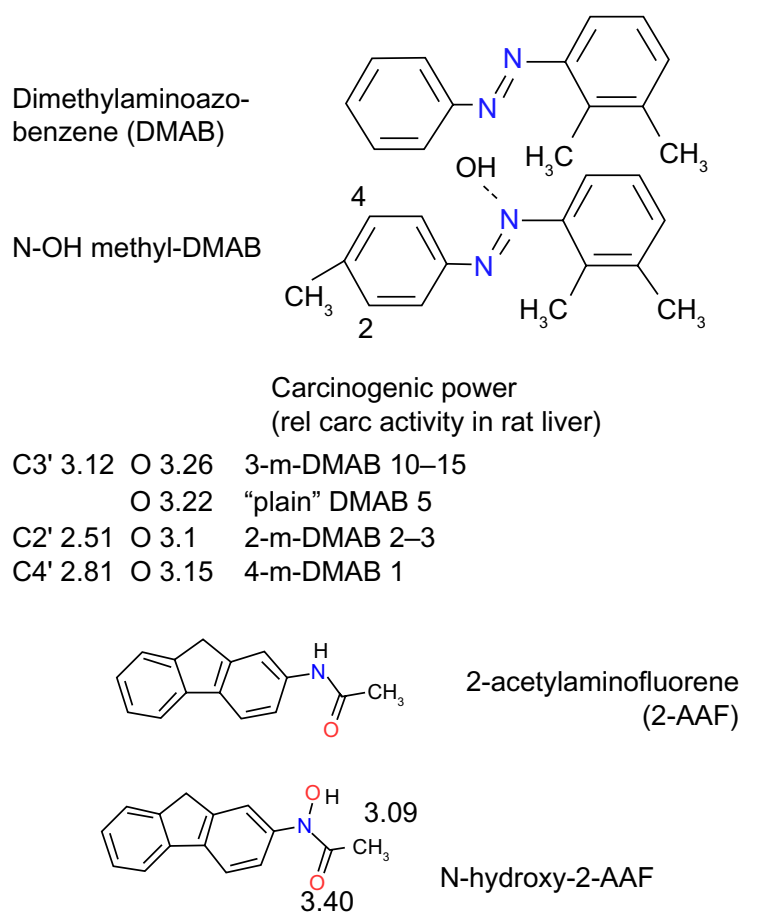

Figure 5 Aromatic amines. Abbreviation: rel carc, relative carcinogenicity.<smiles>Cc1c2ccccc2cc2c3c(ccc12)C(O)C(O)C1=C3O1</smiles><smiles>C=CCC=CC1=C2OC2C2=C1C(O)=C(O)c1ccc3c(c1=C2)=CCC3</smiles>

8,9 diol-10,(11)-epoxidemethyl-BA

(ultimate carcinogens)

\section{3,4-diol-1,(2)-epoxide-methyl-BA}

\section{Authors}

$\begin{array}{ccc}\text { Atoms, } & \text { Dunning } & \text { Stevenson } \\ \text { delta } & \text { No of tumors } & \text { Carcin activity }\end{array}$

$\begin{array}{lrc}\text { C7: } 3.15 & 93 & ++++ \\ \text { C6: } 2.99 & 71 & +++ \\ \text { C8: } 2.92 & 61 & +++ \\ \text { C12: } 2.99 & 52 & +++ \\ \text { C9: } 2.93 & 5 & + \\ \text { C4: } 2.92 & 5 & - \\ \text { C10: } 2.92 & 5 & - \\ \text { C5: } 2.90 & 4 & - \\ \text { C1: } 2.85 & 3 & -\end{array}$

Figure 6 Benzanthracene (BA). Abbreviation: carcin, carcinogenic.

of these carcinogens and as responsible for many different tumors. Pullman et a ${ }^{11,12}$ developed the Bay Region theory in 1955 and attributed carcinogenic activity to adding atoms to the hydrocarbon frame at the $\mathrm{K}$ region, in contrast to at the $\mathrm{L}$ region (with low activity) and the $\mathrm{M}$ region (where metabolic deactivation takes place).

Sims ${ }^{13}$ and Jerina, ${ }^{14}$ succeeding Heidelberger, ${ }^{9,10}$ found 7,8-diol 9-(10)-epoxide-BP (see Figure 7A) to be particularly responsible for binding to DNA. Brooks and Lawley ${ }^{15}$ postulated a quantitative relationship between the extent of DNA binding and carcinogenicity. A similar carcinogenicity shows di-benz(a,i)pyrene (see Figure 7B).

Figures 8 and 9 show some of the alkylating carcinogens transferring alkyl groups, their total molecule, or other groups to ring atoms of nucleophilic nucleotides with a preference for nitrogen, sulfur, and oxygen, whereby the alkylating group replaces a reactive hydrogen. Or they attach them to biologically important functional groups such as amino groups, thiolate anions, or phosphate anions of proteins. This type of alkylating agent, such as $\mathrm{N}$-mustard ( $\Delta 3.21)$, 
A<smiles></smiles>

7,8-diol 9-(10)-epoxide-BP

Carc groups O9' 3.11 (O10' 3.38)

O8' 3.17 (O8' 2.41)

O7' 2.90 (O7' 2.53)

B

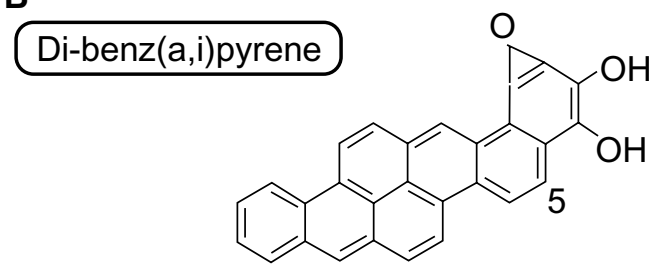

3,4-diol-(1),2-epoxide-di-BP

Carc groups (O1'3.34) O2' 3.13

(O3' 2.41) O3' 3.16

(O4' 2.55) O4' 2.92

Figure 7 (A) Benz(a)pyrene (BP) and (B) di-benz(a,i)pyrene. Abbreviation: Carc, carcinogenic.

cyclophosphamide (O 2.99), and cisplatin (Pt 3.21) work as carcinogens in toto directly on genetic molecules by means of using the most electrophilic group as a point of attack. Busulfan acts directly after being demethylated in the metabolism. Chlorambucil is toxic to the group $\mathrm{O} / \mathrm{OH} 3.74$

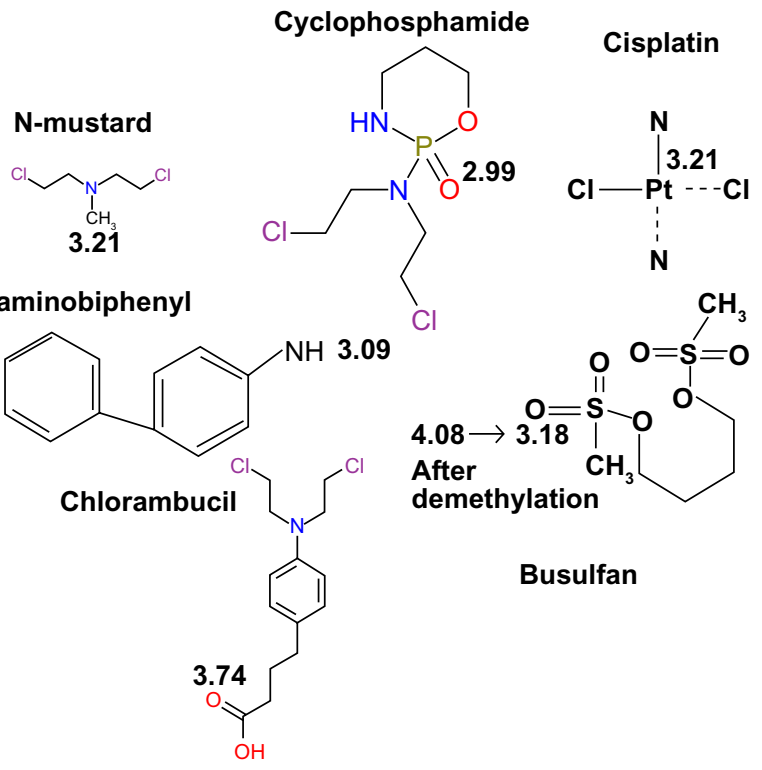

Figure 8 Alkylants.

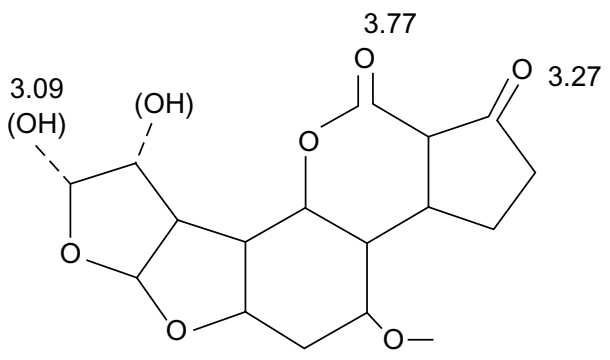

(8,9-epoxides resp 8,9-diol)

Figure 9 Aflatoxin $\mathrm{BI}$.

and yet becomes carcinogenic via the metabolism. The carcinogenic effect of aromatic amines of type 4-aminobiphenyl arises from oxidation, mainly at the N7 ring atom, of the nucleotides. Other aromatic amines, such as benzidine and 2-naphthylamine, show the same group NH (3.09), as well as 4-aminobiphenyl (NH2 3.09), used as a model carcinogen in mutagenic and cancer studies.

Aflatoxin, a product of fungi, is, in its plain B1 form, hepatotoxic ( $\Delta 3.27$ and 3.77) and has to become oxidized to get 8,9-diols or 8,9-epoxides with carcinogenic groups $(\Delta 3.09)$.

\section{The carcinogenic principle}

Reviewing the $\Delta$ values of carcinogens, we came to the conclusion that the critical range of functional groups of molecules for being carcinogenic is between $\Delta 2.70$ and approximately 3.25. Beyond the upper border of the spectrum, the substances increase their reactive abilities but lose their carcinogenic abilities. They end up in the range of either receiving free radicals or acting as toxins.

It should be concluded that all noncarcinogens fall, more or less, out of this spectrum. Then alkylation would mean "initiation" of cancer, and the action of a carcinogen after exerting its alkylating effect, or of another nonalkylating carcinogen, would be the promotion of cancer.

In the process of alkylation, a strong electrophilic group is separated from a weak nucleophilic molecular rest and transferred to form a covalent binding with a strong nucleophilic molecule, leaving a weak electrophilic rest (most common $\mathrm{H}+$ ). The intensity of alkylation correlates well with the calculated molecular electrostatic potential at the reactive site. The molecular electrostatic potential is sequence-dependent and strongly influenced by its nearest neighbor molecule. Nevertheless, among N-mustards with different chemical structures, there are distinct differences, which are not related to their charges but, rather, 
to the structure of their nonalkylating portion. In addition, alkylating cytostatics are distinguished by pharmacokinetics, lipid solubility, and exact chemical reactivity, which is caused by different functional groups independent of carcinogenicity.

To alkylate, there must be a certain amount of difference in the $\Delta$ values to surpass electrostatic cohesion. Similarly, on the side of the reactant, the weak electrophilic group must be separated from the strong nucleophilic molecular part and expulsed. The resulting covalent bindings between alkyl rest or the whole carcinogen and reactant, which means DNA or other biological important molecules, possess a low difference in $\Delta$ values and are stable.

After performing covalent binding, other groups of DNA get a changed $\Delta$ value, which can mean carcinogenicity to the whole molecule or it can concern cancer cells. This alkylation can mean destruction of the cancer cell. Alkylating substances are in use in the therapy of cancer because of their ability to stop DNA production within cancer cells. Unfortunately, however, DNA replication within normal cells will be quite easily disturbed as well, which could mean cell death or initiation of cancer growth itself.

\section{The anticarcinogenic principle}

For the health of individuals, very important organic molecules such as structural molecules and vitamins and hormones have most of their functional groups outside the carcinogenic spectrum. In particular, hormones seem to act on the genes in the sense of positive or negative effectors. In this case, the hormone would at first inactivate the repressor (in the Jacob-Monod model ${ }^{16}$ ) and indirectly activate the gene. The reverse would mean the activation of a repressor and the inactivation of the gene.

More probable than this model would be one that demonstrates that the hormone, which acts as "primary messenger," acts on the enzyme cyclophorase, which catalyzes the transformation of adenosine monophosphate (AMP) to cyclic AMP (cAMP). cAMP activates an enzyme that transfers phosphate groups to proteins such as histones and inactivates their function as stabilizers and repressors of gene activity. Thus, the processes of transcription and translation can commence. In some way, carcinogens seem to be able to interrupt this flow of information.

Hormones and vitamins possess $\Delta$ values of functional groups within the carcinogenic range, by which they are able to displace carcinogenic groups of carcinogens from receptor molecules. Unfortunately, the results of modern studies have indicated that the Janus-faced vitamins possess cancer-protective as well as cancer-arousing abilities. The functional groups situated may displace carcinogens, but they may promote already initiated cancer cells.

In the 1980s, preliminary studies of the effect of antioxidants as anticancerous substances indicated that vitamin $\mathrm{A}$ and beta-carotene reduced the incidence of cancer. Better-prepared studies, beginning in 1985 and ending in 1986, controlled these results. The Finnish Alpha-Tocopherol, Beta-Carotene Cancer Prevention (ATBC) trial and the Beta-Carotene and Retinol Efficacy Trial (CARET) ${ }^{17}$ could not confirm the former results. In particular, the ATBC study concluded that beta-carotene increased the death rate in lung cancer, although probably only for those patients with cell damage that already existed before vitamin application started. The CARET study showed that beta-carotene and vitamin A not only do not lower the lung cancer mortality rate in smokers and asbestos-loaded patients, but could also increase the death rate.

Other studies, such as the Physician Health Study, ${ }^{17}$ did not find an increase or decrease in cancer incidence and of heart and circulation diseases between more or less healthy physicians, either supplemented with vitamins or not. Current scientific evidence is inconsistent as to whether supplements of vitamins can prevent or delay cancer (according to the National Cancer Institute's Cancer Information Service). The call for better guidelines continues.

Functional groups of vitamins and hormones may compete with carcinogens for receptors. Another anticarcinogenic mechanism gets provided by halogenated hydrocarbons, which act by induction or inhibition of microsomial enzymes activating carcinogens by oxidation.

In addition, some alkylating substances, such as inhibitor polycyclic hydrocarbons (flavones), work by competing with carcinogenic polycyclic hydrocarbons for binding to DNA. $^{18}$

Similar to vitamin D3, vitamin A (in Figure 10) has only one hydrophilic group, but several lipophilic groups, causing it to be soluble in fat. Synthetic vitamin A is regarded as potentially cancer-causing. Similar to other important vitamins, vitamin A works as an antioxidant and tumor-inhibiting substance. These effects seem to be independent from the virtual vitamin function. The metabolites of vitamin A, 3-hydroxyl-vitamin A, and retinoic acid possess groups with additional $\Delta$ values far beyond the carcinogenic spectrum and are, accordingly, potentially toxic.

\section{Hormones}

Findings of modern biology suggest that the fate of somatic cells that become cancer cells is destined by 


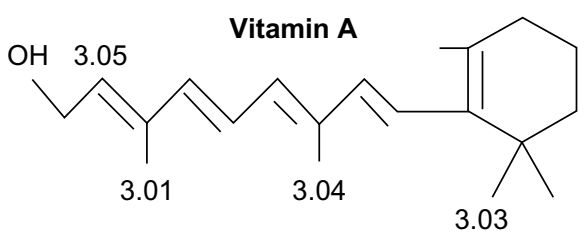

3-Hydroxyvitamin A

3.94
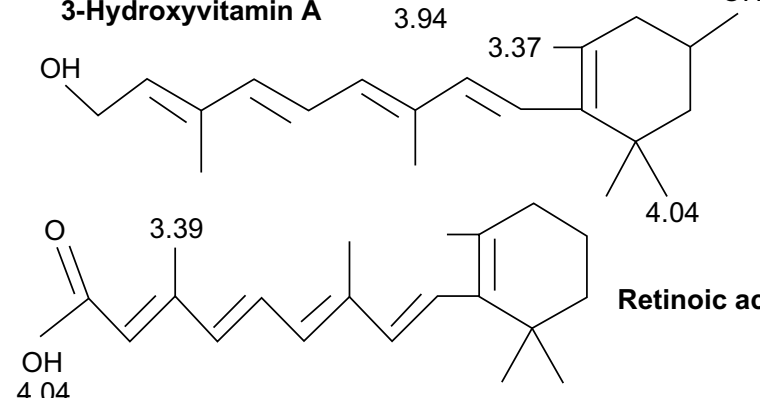

4.04

Retinoic acid

Figure 10 Carotenoids.

genes, or that even cancer cells may be present early in embryonic development. However, the oncoming proliferation and enlargement of those cells have to be stimulated or enhanced by other factors, especially hormones.

If the effect of hormones is directed at cell proliferation, as well as at increasing the protein content of the cells, hormones seem to have some difficulties in discriminating normal cells from cancer cells, and thus can be regarded as potential carcinogens. At the least, hormones are in many respects cocarcinogens. Cocarcinogens are not carcinogens in themselves, but they give a carcinogen support to form

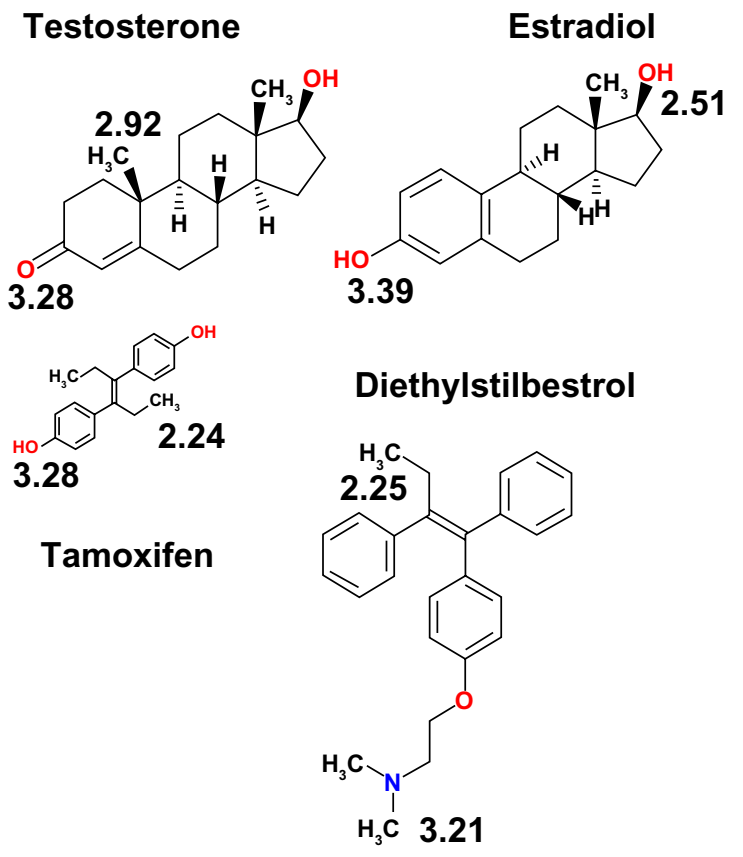

Figure II Sexual hormones.

tumors even if they are found at a dose that would not be carcinogenic without such support.

Some hormones bind directly to chromatin, and protein hormones act by binding to surface membrane proteins, partially by raising or lowering the amount of cAMP, which works as a secondary messenger in cytoplasmic sites. Steroid hormones accumulate (or deplete) specific mRNAs, which would mean that they find a way to activate or deactivate specific sequences of DNA. It is assumed that hormones expose DNA and render it capable for attack by carcinogens. Testosterone has the ability to induce and maintain cell differentiation, and estrogens are suspected to work in the opposite direction, reverting cell mitosis.

The different behaviors of the male and the female sexual hormones are supposed to be based on a kind of antagonism in binding to the cell receptors: estrogens with $\mathrm{C} 17$ keto groups transfer two sulfhydryl groups of a histone molecule to an $\mathrm{S}-\mathrm{S}$ bond, so that RNA polymerase II can be attached to a certain DNA sequence. This procedure allows the formation of RNA and induces protein/enzyme synthesis (eg, DNA polymerase), and thus uncontrolled, enzyme-mediated cell proliferation. In contrast to estrogen, testosterone reactivates the nucleic receptor and stabilizes the histone shield of DNA by the reduction of $\mathrm{S}-\mathrm{S}$ bridges to $\mathrm{S}-\mathrm{H}$ groups by means of its $\mathrm{C} 17 \mathrm{OH}$ group. The specificity of a receptor is not absolute, so it will be occupied by molecules that are not very structurally similar or be forced to change its constellation by antagonistic hormones.

It seems that the groups $\mathrm{O}=$ and $\mathrm{OH}-$ at position $3^{\prime}$ and similar atoms are important for action on hormone receptors. Like testosterone (as seen in Figure 11), progesterone has the $\Delta$ value of the position 3'3.28 (not depicted here), cortisone 3.25. Diethylstilbestrol has an $\mathrm{OH}$ group with $\Delta 3.28$, and the antihormones tamoxifen $\mathrm{C} 3(\Delta 3.21)$, finasteride $\mathrm{OH}(\Delta$ 3.28), and flutamide $\mathrm{OH}(\Delta 3.31)$ possess the same or very similar groups as the hormones cited, including the vitamin ergocalciferol which possesses $\mathrm{OH}(\Delta 3.28)$ as well.

\section{Summary}

Cancer research at this time is searching for the primary target of attacking chemical carcinogens, and to identify the exact mechanism of the attack.

Chemicals can act as initiators or promoters of cancer cell growth. The primary act seems to be the alkylation of DNA, RNA, or proteins and the formation of covalent bonds with them; the secondary act is the promoting effect of the same or other carcinogens, or other contributing factors, such as hormones. 
Chemical carcinogens cover a wide variety of chemical structures, steric constructs, and molecular weight. Not all carcinogens show common features in chemical reactivity, solubility and dispersion, location, and behavior of molecular side groups, as well as steric similarities.

The aim of this article is to find a general basis for carcinogenic strength of carcinogens leading to the cancerous conversion of DNA. Here, the possibility of influences on genes by noncovalently bound molecules and without explicit structural changes of DNA cannot be ruled out.

Some chemical substances have to be metabolically converted to become the ultimate carcinogen.

All carcinogens are more or less strong electrophilic reagents. In some respect, carcinogenicity seems to be dependent on the strength of electrophilicity. The electrophilic sites of the compounds react with the nucleophilic sites of genetic information-bearing molecules. Although in most cases strong carcinogens transfer their electrophilic groups to genetic material or form covalent bonds through them, weaker carcinogens or cocarcinogens interact by means of noncovalent bonds and act by promotion, whereas the covalent bonds initiate cancer.

Carcinogens and cocarcinogens seem to modify enzymatic and immune responses and promote cancer growth in a way secondary to that of already initiated cancer cells. One assumes that hormones and vitamins may protect healthy cells from being converted into cancer cells and that they may promote initiated cancer cells, depending on their effective functional groups.

The side groups of carcinogens determine whether they are hydrophilic or lipophilic, and then influence the organotrophy. Important primary lipophilic carcinogens such as benz(a)pyrene (BP), benzanthracene (BA), and 3-methylcholanthrene (MC) have to be metabolically oxidized to epoxides and diols to become hydrophilic, with organ specificities. Carcinogenicity seems to be exerted from lipophilic as well as from hydrophilic side groups.

Cellular health seems to be dependent on the stable and harmonic conformation of DNA and the undisturbed base pairing. Alkylation or forming of covalent bonds of carcinogens to DNA disturbs these physiological conditions profoundly, and it is thought that this causes cancer.

It is generally agreed that only a simple alkylation of one base of DNA shifts the conformation of DNA from one form to the other and changes its function. Such helical changes could dramatically alter repressor (or activator) binding and gene function. Both carcinogens and hormones can influence gene action indirectly by working on sulfur bridges of the histone molecule and on their phosphate bonds to DNA.

Enzymatic proteins are involved in the protective mechanism of an organism. Take, for example, oxidases caring for the oxidative removal of chemicals. Unfortunately, the addition of oxygen or hydroxyl groups to a chemical substance can mean carcinogenic activation or transformation to a hazardous substance. When electrophilic groups or free radicals are produced, something similar occurs.

The objective of this research was to find an initial way to describe the interaction of carcinogens, vitamins, and hormones with genetic material using a mathematically formalized system. The so-called $\Delta$ values were described and made calculable in former publications by the author. Their amount directly determined the measure of molecular interaction, electrophilicity, and carcinogenic strength and defined the chemical structure of points of attack of atomic groups to receptors. To understand the interaction of molecules mathematically, a combinatory technique had to be applied to summarize the effect of a multitude of atoms of a molecule. Atoms were used as mathematical elements and transformed into numerical values that simplified complexity. So, atoms and side groups of interacting molecules could be handled as digits.

Side groups direct primarily biological effects, serve as hydrogen acceptors or donators, and determine solubility if a substance is lipophilic or hydrophilic. In addition, side groups can be transferred to alkylates or oxidize other molecules, and they can also form free radicals. All types of side groups, whether nonpolar or polar, hydrophile or lipophile, or electrophile or nucleophile, contribute to the receptor function, initiate structural changes, or take care of the stability of a structure. According to a current theory, the ability to form tight bonds with DNA is positively correlated with carcinogenic strength.

It can be demonstrated in this article that an amount of the difference in the $\Delta$ values of the functional groups of benzanthracene, methylated dimethylaminoazobenzol, and possibly the nitrosamines are correlated to the carcinogenic strengths of those compounds. Physical and chemical factors determine species and organ specificity. It remains an open question whether the $\Delta$ values contribute as well.

Most functional groups of hormones and vitamins have their $\Delta$ values fall beyond the limits of the spectrum that is believed to be carcinogenic. However, some groups of those substances fall within the limits. Perhaps the Janus-faced ability, particularly of some hormones, can be professed in such a way. They are both potentially carcinogenic and 
noncarcinogenic and, respectively, able to compensate for the carcinogenic potency of carcinogens.

As for the carcinogens, the type and the differences of the $\Delta$ values of their side groups determine whether hormones and, possibly, vitamins and other substances tend to be carcinogenic or noncarcinogenic, or even anticarcinogenic.

One of the practical advantages use of the $\Delta$ values can offer seems to be keeping at hand a tool to judge realistically the risk of carcinogenicity hidden in chemicals in our environment or those being used in drugs or additives in our food.

Every chemical exposing functional groups with differences of $\Delta$ values indicative of cancer has to be examined carefully. It appears, however, that one or two groups can have their cancerous potency compensated for by an abundance of noncarcinogenic groups in hormones and vitamins. Similarly, chemicals with singular carcinogenic groups may be compensated in full by noncancerous or anticancerous-acting substances. This seems to be the principle of anticarcinogenesis.

The investigations of substances known to be alkylating or oxygenizing of genetic macromolecules or transforming other substances into ultimate carcinogens demonstrate that alkylating means a special form of exposing and action of carcinogenic groups. Alkylating cytostatics in use are able not only to transform other substances into carcinogens but also can act beneficially as anticancer drugs. The task of cancer therapy of the future is not only to find and use such anticarcinogenic drugs for the sake of patients with cancer but also to avoid adverse effects in the form of arousing cancer by themselves. That would mean designing drugs possessing only anticarcinogenic side groups without carcinogenic components, but maintaining organic and species specificities.

The relation of carcinogenic and anticarcinogenic groups within a molecule could indicate how we could understand the phenomena of resistance to cancer therapy. A substance acts as an anticancer drug as long as its functional groups do. When all its anticancer groups are spent, the remaining carcinogenic groups start to work, and the drug becomes ineffective or even carcinogenic itself.

Anticarcinogenic groups do not only work by compensating carcinogenic groups directly but also may act by inducing antitoxic or anticarcinogenic enzyme systems. Even carcinogens in weak, homeopathic concentrations are able to induce such effective anticarcinogenic enzymes. Thus, in many respects, the dosage seems to decide whether a substance acts as poison or as a drug.

Therefore, not only the relation of carcinogenic to anticarcinogenic groups within a molecule, but also the total number of available groups, seems to determine sickness and health. After all, it is unsurprising that experimental data (eg, for the development of resistance against glucocorticoids in proliferative cells of lymphatic origin) show a drastically reduced number of receptors for glucocorticoids per cell compared with sensitive cells. ${ }^{14}$

We must remember the conditions in mammary tumors, where the absolute count of estrogen or progesterone receptors decides which therapeutic intervention we use as well as the fate of the patients.

\section{Disclosure}

The author reports no conflicts of interest in this work.

\section{References}

1. Singer B. The effect of base modification on fidelity in transcription. In: Pullman B, Ts'o POP, Gelboin H, editors. Carcinogenesis: Fundamental Mechanisms and Environmental Effects. Houten: Springer Netherlands; 1980:91-102.

2. Holden C. Albert-Szent-Györgyi, electrons, and cancer. Science. 1979;203(4380):522-524.

3. Szent-Györgyi A. Studies on biological oxidation and some of its catalysts. Eggenberger Publ. 1973; Budapest, Hungary.

4. Schmidt HF. The genetic code. An arithmetical interpretation. Marburg, Germany: Tectum Verlag; 1996.

5. Schmidt FH. Biological genesis: the first step from dead matter to life. A contribution to the nature of DNA, RNA, and the genetic code. Res Rep Biol. 2013;4:1-9.

6. Möller J, Schmidt FH. Delta Values, a program. GN General Public License. Boston: Free Software Foundation, Inc; 1989.

7. Druckrey H, Ivankovic S, Preussmann R. Organotrope carcinogene Wirkungen. Z Krebsforschg. 1977.

8. O'Connor PJ. N-nitroso Compounds Analysis, Formation and Occurrence. Br J Cancer. 1981;44(5):767-768.

9. Heidelberger C, Moldenhauer MG. Cancer Res. 1947;13:246, 250-255.

10. Heidelberger C, Moldenhauer MG. The interaction of carcinogenic hydrocarbons with tissue constituents. IV. A quantitative study of the binding to skin proteins of several C14-labeled hydrocarbons. Cancer Res. 1956;16(5):442-449.

11. Pullman A, Pullman B. Electronic structure and carcinogenic activity of aromatic molecules; new developments. Adv Cancer Res. 1953:117-169.

12. Pullman B, Ts'o POP, Gelboin H, editors. Carcinogenesis: Fundamental Mechanisms and Environmental Effects. Houten: Springer Netherlands; 1980.

13. Sims P. Dihydrodiols and diol-epoxydes in the activation and detoxification of polycyclic hydrocarbons. In: Pullman B, Ts'o POP, Gelboin H, editors. Carcinogenesis: Fundamental Mechanisms and Environmental Effects. Houten: Springer Netherlands; 1980:33-42.

14. Jerina DM, et al. Carcinogenicity of Polycyclic Aromatic Hydrocarbons: The Bay-Region Theory. In: Pullman B, Ts'o POP, Gelboin H, editors. Carcinogenesis: Fundamental Mechanisms and Environmental Effects. Houten: Springer Netherlands; 1980:1-12.

15. Brooks, Lawley. Quantitative relations between extent of DNA-binding and carcinogenicity.

16. Jacob F, Monod J. Genetic regulatory mechanisms in the synthesis of proteins. J Mol Biol. 1961;3:318-356.

17. Greenwald P, Anderson D, Nelson SA, Taylor PR. Clinical trials of vitamin and mineral supplements for cancer prevention. Am J Clin Nutr. 2007;85(1):314S-317S.

18. Goldstein A. Principles of Drug Action: The Basis of Pharmacology. New York: John Wiley \& Sons Inc; 1974. 
Research and Reports in Medicinal Chemistry

Dovepress

\section{Publish your work in this journal}

Research and Reports in Medicinal Chemistry is an international, peerreviewed, open access journal publishing original research, reports, reviews and commentaries on all areas of medicinal chemistry. The manuscript management system is completely online and includes a very quick and fair peer-review system, which is all easy to use.

Submit your manuscript here: http://www.dovepress.com/research-and-reports-in-medicinal-chemistry-journal
Visit http://www.dovepress.com/testimonials.php to read real quotes from published authors. 